\title{
On the Development of a Very Rapid Gas Chromatographic Method for the Analysis of High Molecular Weight Hydrocarbons in Cigarette Smoke*
}

\author{
by \\ W.M. Coleman, III and Bert M. Gordon \\ R. J. Reynolds Tobacco Company, P.O. Box 1487, Winston-Salem, NC 27102-1487, USA
}

\section{SUMMARY}

A very rapid, flash-gas chromatographic (GC), quantitative method for the analysis of high molecular weight saturated hydrocarbons in cigarette smoke has been developed. The method was fast, accurate and precise. Sample turn around times were approximately six minutes, with an accompanying average percent relative standard deviation (\%RSD) of less than $10 \%$. Four linear saturated hydrocarbons with 27, 29, 31 and 33 carbon atoms were quantitated in an array of reference cigarettes ranging in "tar" deliveries from approximately 2 to approximately $20 \mathrm{mg}$. By use of a cyclohexane extraction of cigarette smoke captured on Cambridge filter pads, the extraction efficiency was determined to be greater than $95 \%$ for each hydrocarbon. The approach represents a significant advance over current analytical procedures that require, on average, greater than 30-min sample turn around times. [Beitr. Tabakforsch. Int. 20 (2003) 348-354]

\section{ZUSAMMENFASSUNG}

Eine sehr schnelle gaschromatographische ("Flash-GC"), quantitative Methode zur Analyse gesättigter Kohlenwasserstoffe mit hohem Molekulargewicht im Zigarettenrauch wurde entwickelt. Diese Methode zeichnet sich durch ein hohes Maß an Schnelligkeit, Richtigkeit und Präzision aus. Die Probendurchlaufzeit beträgt ungefähr sechs Minuten mit einer durchschnittlichen relativen Standardabweichung (\%RSD) von weniger als $10 \%$. Vier lineare gesättigte Kohlenwasserstoffe mit 27, 29, 31 und 33 Kohlenstoffatomen wurden in einer Reihe von Referenzzigaretten gemessen, deren Kondensatgehalt bei ungefähr 2 bis $20 \mathrm{mg}$ lag. Durch Extraktion des auf Cambridgefiltern aufgefangenen Zigarettenrauchs mit Cyclohexan wurde be- stimmt, dass die Extraktionseffizienz bei jedem Kohlenwasserstoff mehr als $95 \%$ betrug. Dieser Ansatz bietet einen bedeutenden Fortschritt gegenüber gegenwärtigen analytischen Methoden, deren Probendurchlaufzeit durchschnittlich mehr als 30 Minuten beträgt. [Beitr. Tabakforsch. Int. 20 (2003) 348-354]

\section{RESUME}

Une méthode quantitative très rapide de chromatographie gazeuse 'flash" pour l' analyse des hydrocarbures saturés de poids moléculaire élevé dans la fumée de cigarette a été développée. La méthode est rapide, exacte et précise. La durée de passage des échantillons est d' environ 6 minutes avec un écart-type relatif moyen de moins de $10 \%$. Quatre hydrocarbures saturés linéaires avec 27,29, 31 et 33 atomes de carbone ont été dosés dans une gamme de cigarettes de références avec un rendement en goudron d' environ 2 à 20 mg. En utilisant le cyclohexane pour l' extraction de la fumée de cigarette recueillie sur filtre Cambridge, il a été déterminé que l' efficacité d' extraction était supérieure à 95\% pour chaque hydrocarbure. Cet approche offre des avantages importants par rapport aux procédures analytiques actuelles qui nécessitent, en moyenne, plus de 30 minutes pour la préparation des échantillons. [Beitr. Tabakforsch. Int. 20 (2003) 348-354]

\section{INTRODUCTION}

In 1954 hentriacontane was listed as the only alkane identified in tobacco smoke (1). Since this initial disclosure, over 100 alkanes ranging from methane, $\mathrm{C}_{1}$, to hexatriacontane, $\mathrm{C}_{36}$, have been identified in cigarette smoke (2-15). The hydrocarbons found in cigarette smoke conden- 
sate consist primarily of normal, iso, and anteiso isomers from $\mathrm{C}_{12}$ to $\mathrm{C}_{40}(3,16)$. More specifically, the major hydrocarbons in cigarette smoke have been identified as $\mathrm{C}_{27}, \mathrm{C}_{29}$, $\mathrm{C}_{31}$ and $\mathrm{C}_{33}$ with normal and iso isomers being present $(2,4,5)$. The analytical methods employed for the qualitative and semi-quantitative analysis of cigarette smoke for these hydrocarbons have been somewhat dated, having employed packed column technologies for the end determinations $(4,5)$. Typical separation times for these analytes with the packed column technologies were in excess of one hour. In addition, with somewhat extensive sample preparation times the overall analysis time was rather long and involved. A more recent study of hydrocarbons of this type in cigarette smoke resorted to the determination of the high molecular weight hydrocarbon octatriacontane, $\mathrm{C}_{38}$, by employing high performance liquid chromatography (HPLC) (6). The retention time of the $\mathrm{C}_{38}$ analyte was approximately $13 \mathrm{~min}$.

The recently renewed interest in hydrocarbons in cigarette smoke is based in part on the hypothesis that the hydrocarbons present in tobacco are precursors to polynuclear aromatic hydrocarbons found in mainstream tobacco smoke (7,12-14). In addition, an accurate and precise assessment of these hydrocarbons in tobacco smoke could facilitate further understandings of their proposed role in the inhibition of tumorigenicity of mouse skin to polynuclear aromatic hydrocarbons as discussed in detail by RODGMAN (14), WYNDER and HOFFMANN (15). Given the extended sample analysis times indicated by the published literature, a more facile overall analytical approach was required. Capillary gas chromatographic systems often use a relatively cool initial oven temperature to ensure that relatively low boiling components can be efficiently separated from the higher boiling components of the sample. To ensure reasonable sample analysis times, column oven temperature programming is often employed to optimize the elution times of the higher boiling components. Once the higher boiling components have eluted from the column, the column oven, now at an elevated temperature, is then allowed to return to the often much cooler initial temperature. With the temperature precision of modern gas chromatographs, very precise elution times can be achieved with complex mixtures having wide ranges in boiling points. However, in a number of cases the time required for the column oven to return to the initial value adds substantial overhead time to the overall analysis time, sometimes several minutes. Thus, the ability to reduce the time required to reach column oven thermal equilibrium prior to the next analysis would be a key to reducing overall sample analysis time. In addition, the column oven temperature programming rates are somewhat limited by the necessity to heat the entire oven mass evenly and in a reproducible fashion.

Alternatively, an approach aimed at heating only the column and not the entire column oven environment would seem to be an acceptable way to impact the time required to reach initial thermal equilibrium. That is, heating only the mass of the column vs. the mass of the oven would create the potential for shortening the time required to reach initial thermal equilibrium, thus shortening the overall analysis time. Such capability to heat only the column exists with commercial instrumentation termed ezFLASH, from TDX, Chelmsford, MA. With this technology the column itself can be reproducibly ballistically heated, up to approximately $20^{\circ} \mathrm{C}$ per second, to the maximum temperature value of the column. Equally important is the capability of the column to return to initial thermal equilibrium in seconds. By coupling the capability to heat the column rapidly with the rapid return to initial thermal equilibrium and capillary column technology, the potential exists to significantly reduce analysis times, for volatile and semivolatile components.

There are some very important fundamental chromatographic parameters that must be addressed when considering significantly reducing the elution times of analytes from, for example, multiple minutes to just a few minutes or even seconds. Possibly the most important is the efficiency of the capillary column. Reduction in capillary column internal diameter has been documented to have a pronounced positive impact on the efficiency of columns. Therefore, narrow bore fused silica capillary columns, $\leq 250-\mu \mathrm{m}$ internal diameter are appropriate starting points when employing the ezFLASH technology.

In the past few years, applications of the ezFLASH technology have appeared (7-20). These applications confirmed the ruggedness of the ezFLASH approach to various analytes and in particular one of the references presented data on a set of relatively low molecular weight hydrocarbons (17). More specifically, $\mathrm{C}_{9}$ through $\mathrm{C}_{17}$ hydrocarbons were separated in approximately $10 \mathrm{sec}$ with a flame ionization detector. Thus, based on a theoretical evaluation and actual reports of the potential of ezFLASH gas chromatography to positively impact hydrocarbon analyses parameters, a series of experiments involving the analyses of actual high molecular weight hydrocarbons in cigarette smoke was initiated. This report will describe the results of the investigations in terms of analysis time, analysis accuracy and precision.

\section{EXPERIMENTAL}

\section{Sample preparation}

During the course of development of the analytical procedure two smoking approaches were evaluated: 1) linear 20port smoking with collection on a Cambridge filter pad and 2) rotary 20-port smoking with collection by electrostatic precipitation (ESP). In both cases, the cigarette products were conditioned and smoked strictly following the protocols of the Federal Trade Commission (FTC). In the ESP experiments, three traps, containing solvent at $0{ }^{\circ} \mathrm{C}$ (ice bath), were placed after the ESP tube to test for analyte break through. No hydrocarbons were detected in the traps. After thorough evaluation of both smoke collection procedures, procedure one was adequate to collect the linear high molecular weight hydrocarbons. Thus, collection of the mainstream particulate phase was accomplished with the Cambridge filter pad (Table 1).

Numerous solvents and solvent volumes were evaluated for extraction efficiency and ease of use during the development of the approach, Table 1. The mainstream smoke from a low "tar" market product was used to examine various parameters of the sample workup procedure. The solvents/solvent mixtures included: 1) cyclohexane; 2) cyclo- 
Table 1. Comparison of smoke collection approaches using different solvents for extraction, solvent volume $25 \mathrm{~mL}$

\begin{tabular}{|c|c|c|c|c|c|c|}
\hline Sample & Solvent & $\begin{array}{c}\mathrm{C}_{27} \\
(\mu \mathrm{g} / \mathrm{cig})\end{array}$ & $\begin{array}{c}\mathrm{C}_{29} \\
(\mu \mathrm{g} / \mathrm{cig})\end{array}$ & $\begin{array}{c}\mathrm{C}_{31} \\
(\mu \mathrm{g} / \mathrm{cig})\end{array}$ & $\begin{array}{c}\mathrm{C}_{33} \\
(\mu \mathrm{g} / \mathrm{cig}) \\
\end{array}$ & $\begin{array}{c}\text { Total } \\
(\mu \mathrm{g} / \mathrm{cig})\end{array}$ \\
\hline ESP trap & Cyclohexane & 14.90 & 14.40 & 36.75 & 16.24 & 82.29 \\
\hline ESP trap & Cyclohexane/chloroform 80/20 (v/v) & 14.17 & 13.96 & 34.68 & 16.07 & 78.88 \\
\hline ESP trap & Cyclohexane/chloroform 50/50 (v/v) & 14.04 & 14.00 & 35.12 & 16.67 & 79.83 \\
\hline ESP trap & Cyclohexane/methylene chloride 80/20 (v/v) & 13.30 & 13.26 & 32.13 & 15.48 & 74.17 \\
\hline ESP trap & Cyclohexane/methylene chloride 50/50 (v/v) & 14.18 & 14.06 & 35.75 & 17.49 & 81.48 \\
\hline ESP trap & Cyclohexane/toluene 80/20 (v/v) & 13.77 & 13.75 & 34.20 & 16.70 & 78.42 \\
\hline Pad & Cyclohexane & 14.58 & 14.57 & 37.16 & 18.59 & 84.90 \\
\hline Pad & Cyclohexane/chloroform 80/20 (v/v) & 13.77 & 13.97 & 34.87 & 17.37 & 79.98 \\
\hline Pad & Cyclohexane/chloroform 50/50 (v/v) & 14.66 & 14.75 & 38.32 & 19.15 & 86.88 \\
\hline Pad & Cyclohexane/methylene chloride 80/20 (v/v) & 14.37 & 14.55 & 36.56 & 18.58 & 84.06 \\
\hline Pad & Cyclohexane/methylene chloride 50/50 (v/v) & 14.61 & 14.88 & 38.29 & 19.81 & 87.59 \\
\hline Pad & Cyclohexane/toluene 80/20 (v/v) & 14.70 & 14.79 & 38.19 & 19.68 & 87.36 \\
\hline
\end{tabular}

Table 2. Extraction efficiencies

\begin{tabular}{|c|c|c|c|c|c|c|}
\hline Sample & $\begin{array}{l}\text { WTPM } \\
\text { (mg/cig) }\end{array}$ & Amount & $\mathrm{C}_{27}$ & $\mathrm{C}_{29}$ & $\mathrm{C}_{31}$ & $\mathrm{C}_{33}$ \\
\hline \multicolumn{7}{|c|}{ First Extract ( $\mu g / c i g)$} \\
\hline \multirow[t]{2}{*}{ 2R1F } & 27.5 & AVG & 17.61 & 20.08 & 87.85 & 30.48 \\
\hline & & \%RSD & 2.38 & 5.22 & 4.07 & 4.52 \\
\hline \multirow[t]{2}{*}{ 1R3F } & 19.4 & AVG & 12.09 & 13.66 & 63.26 & 22.53 \\
\hline & & \%RSD & 5.81 & 6.33 & 4.36 & 8.61 \\
\hline \multirow[t]{2}{*}{$1 \mathrm{R} 5 \mathrm{~F}$} & 2.1 & AVG & 1.29 & 1.59 & 8.04 & 2.53 \\
\hline & & $\%$ RSD & 3.07 & 8.73 & 5.69 & 8.94 \\
\hline \multirow[t]{2}{*}{ 1R4F } & 10.8 & AVG & 6.45 & 7.91 & 41.88 & 13.07 \\
\hline & & $\%$ RSD & 6.21 & 8.88 & 4.43 & 9.23 \\
\hline \multicolumn{7}{|c|}{ Second Extract ( $\mu \mathrm{g} / \mathrm{cig})$} \\
\hline \multirow[t]{2}{*}{ 2R1F } & 27.5 & AVG & 1.18 & 1.25 & 5.67 & 2.19 \\
\hline & & $\%$ RSD & 6.15 & 11.36 & 8.16 & 9.58 \\
\hline \multirow[t]{2}{*}{ 1R3F } & 19.4 & AVG & 0.83 & 0.81 & 3.41 & 1.52 \\
\hline & & $\%$ RSD & 9.56 & 15.75 & 7.31 & 10.4 \\
\hline \multirow[t]{2}{*}{ 1R5F } & 2.1 & AVG & 0.06 & 0.06 & 0.41 & 0.19 \\
\hline & & \%RSD & 29.1 & 32.64 & 8.94 & 14.5 \\
\hline \multirow[t]{2}{*}{ 1R4F } & 10.8 & AVG & 0.47 & 0.43 & 1.79 & 0.90 \\
\hline & & $\% R S D$ & 10.3 & 18.95 & 8.38 & 10.0 \\
\hline \multicolumn{7}{|c|}{ Check Standards $(\mu g / m L)$} \\
\hline \multirow[t]{3}{*}{ STD 10} & & AVG & 9.97 & 10.07 & 10.23 & 10.73 \\
\hline & & $\%$ RSD & 2.32 & 4.13 & 2.86 & 4.44 \\
\hline & & \%Error & -1.26 & 0.73 & -0.70 & 1.21 \\
\hline \multirow[t]{3}{*}{ STD 5} & & AVG & 5.07 & 5.20 & 5.29 & 5.57 \\
\hline & & \%RSD & 3.05 & 7.70 & 6.54 & 7.68 \\
\hline & & \%Error & 0.45 & 4.03 & 2.75 & 5.10 \\
\hline \multirow[t]{3}{*}{ STD 1} & & AVG & 1.04 & 1.12 & 1.14 & 1.24 \\
\hline & & $\%$ RSD & 3.09 & 9.98 & 10.1 & 15.6 \\
\hline & & \%Error & 2.95 & 11.7 & 10.7 & 16.7 \\
\hline \multirow[t]{3}{*}{ STD 0.2} & & AVG & 0.20 & 0.18 & 0.22 & 0.23 \\
\hline & & $\%$ RSD & 5.28 & 22.1 & 7.05 & 9.05 \\
\hline & & \%Error & 0.11 & -12.1 & 5.27 & 8.96 \\
\hline
\end{tabular}

hexane/chloroform 80/20 (v/v); 3) cyclohexane/chloroform $50 / 50(\mathrm{v} / \mathrm{v}) ; 4)$ cyclohexane/methylene chloride $80 / 20(\mathrm{v} / \mathrm{v})$; 5) cyclohexane/methylene chloride $50 / 50(\mathrm{v} / \mathrm{v})$; and 6$)$ cyclohexane/toluene 80/20 (v/v). Solvent volumes of 25, 50 and $100 \mathrm{~mL}$ were evaluated. All solvents were prepared with a known concentration of an internal standard, triacontane- $\mathrm{d}_{62}, \quad \mathrm{C}_{30} \mathrm{D}_{62}$, (Aldrich Chemical Company, Milwaukee, WI, USA) at approximately $20 \mu \mathrm{g} / \mathrm{mL}$. After thorough evaluation of these solvents, cyclohexane, $25 \mathrm{~mL}$, was selected based on extraction efficiency and ease of use, Table 1.

Further tests were conducted to establish the volume of cyclohexane required to obtain acceptable analyte extraction efficiency and analyte responses. Four cigarettes obtained from the Tobacco and Health Research Institute at the University of Kentucky were used in the study: 1) 2R1F; 2) 1R3F; 3) 1R5F and 4) 1R4F. The results of these experiments are shown in Table 2 . In these experiments the pad was extracted with $25 \mathrm{~mL}$ of cyclohexane as described above. Twenty-three milliliters were then removed and an aliquot placed in a GC autosampler vial (First Extract). Another $25 \mathrm{~mL}$ of extraction solution was then added to the flask containing the pad and the $2 \mathrm{~mL}$ of remaining extraction solution and re-extracted. An aliquot of this was then placed in an autosampler vial (Second Extract). In this table, WTPM is the wet total particulate matter (which is related to the "tar" level of the cigarette). All samples were smoked six times and each of the six replicates were injected into the GC system six times and the average of these 36 replicates are shown in Table 2 . The results from this experiment indicate that $25 \mathrm{~mL}$ of cyclohexane per pad was adequate to obtain extraction efficiencies of, within experimental error, $100 \%$, regardless of the nominal "tar" value of the cigarettes, with accompanying acceptable analyte responses. The extraction efficiencies were calculated as follows: 1 ) the amount of the First Extract was $M_{1 \mathrm{st}}$ $=x^{*} M_{\mathrm{HC}}$, where $M_{1 \mathrm{st}}=$ amount of First Extract and $M_{\mathrm{HC}}=$ amount of high molecular weight hydrocarbon and $x=$ efficiency; 2) after adding a second $25 \mathrm{~mL}$ to the flask containing the $2 \mathrm{~mL}$ of remaining extraction, the amount in the Second Extraction was $M_{2 \mathrm{nd}}=\left(2 * M_{1 \mathrm{st}} / 25\right)+(1-x) * M_{\mathrm{HC}}$. Solving for $x$, the efficiency, yields $x=M_{1 \mathrm{st}} /\left(M_{2 \mathrm{nd}}+\right.$ $\left.23 / 25 * M_{1 \mathrm{st}}\right)$.

Thus, the final sample preparation procedure was as follows: to one pad containing the mainstream particulate material from 5 cigarettes in a $125-\mathrm{mL}$ Erlenmeyer flask was added $25 \mathrm{~mL}$ of cyclohexane containing a known concentration of internal standard. The flask was stoppered and sonicated in a Branson (Danbury, CT, USA) Model 5200 Sonic Bath for $30 \mathrm{~min}$. Next a portion of the extract was transferred to a $1.8-\mathrm{mL}$ vial, capped and placed in the autosampler for the chromatographic end determination. 
Table 3. Chromatographic conditions

\begin{tabular}{ll}
\hline \multicolumn{1}{c}{ Operating parameters } & \\
\hline \multicolumn{2}{c}{ FLASH conditions } \\
Injector temperature & \\
Detector temperature & $320^{\circ} \mathrm{C}$ \\
Column temperature & $325^{\circ} \mathrm{C}$ \\
$185^{\circ} \mathrm{C}$ & \\
$190^{\circ} \mathrm{C}$ & $0 \mathrm{sec}$ \\
$220^{\circ} \mathrm{C}$ & $35 \mathrm{sec}$ \\
$325^{\circ} \mathrm{C}$ & $40 \mathrm{sec}$ \\
$325^{\circ} \mathrm{C}$ & $185 \mathrm{sec}$ \\
& $230 \mathrm{sec}$ \\
& \\
Oven initial temperature & $160{ }^{\circ} \mathrm{C}$ \\
Hold time & $0.6 \mathrm{~min}$ \\
Temperature program rate & $50.0^{\circ} \mathrm{C} / \mathrm{min}$ \\
Final temperature & $270{ }^{\circ} \mathrm{C}$ \\
Final time & $1.0 \mathrm{~min}$ \\
Detector & $\mathrm{FID}$ \\
Detector temperature & 325 \\
Injection technique & $\mathrm{Splitless}$ \\
Purge time & $30 \mathrm{seC}$ \\
Splitter flow rate & $50.0 \mathrm{~mL} / \mathrm{min}$ \\
Injection volume & $1.0 \mu \mathrm{L}$ \\
Injector temperature & $320{ }^{\circ} \mathrm{C}$ \\
&
\end{tabular}

\section{Standard preparation}

Heptacosane $\left(\mathrm{C}_{27}\right)$, nonacosane $\left(\mathrm{C}_{29}\right)$, hentriacontane $\left(\mathrm{C}_{31}\right)$ and tritriacontane $\left(\mathrm{C}_{33}\right)$ were obtained from Fluka Chemical Corporation, Milwaukee, WI, USA. Standards were prepared gravimetrically in cyclohexane containing the internal standard, $\mathrm{C}_{30} \mathrm{D}_{62}$, obtained from Aldrich Chemical Company, Milwaukee WI, USA. The internal standard concentration in the extracting solution and the standards was approximately $20 \mu \mathrm{g} / \mathrm{mL}$ and the standard concentrations ranged from $10 \mu \mathrm{g} / \mathrm{mL}$ to $0.2 \mu \mathrm{g} / \mathrm{mL}$.

\section{Instrumental parameters}

To an Agilent 6890 (Wilmington, DE, USA) gas chromatograph (GC)fitted with a flame ionization detector (FID) was attached an ezFLASH unit from TDX, Thermedics Detection, Inc., Chelmsford, MA, closely following the manufacturer's installation instructions. Once installed, the Agilent 6890 GC was fitted with a capillary column having the following attributes: length, $5 \mathrm{~m}$; internal diameter, 250 $\mu \mathrm{m}$; film thickness, $0.1 \mu \mathrm{m}$; film type, DB-5MS (J\&W Scientific, Folsom, CA, USA). The carrier gas was helium. The overall instrument operating parameters, including both the ezFLASH and AGILENT 6890 GC (ezFLASH/GC/FID), are disclosed in Table 3.

\section{RESULTS AND DISCUSSION \\ Initial separation investigations}

In the initial stages of method development, separations were attempted employing an Agilent 6890 GC fitted with an Agilent 5973 mass selective detector (MSD). The mass spectrometer was operated in the total ion current mode due in part to the relatively abundant amounts of the selected hydrocarbons in cigarette smoke reported in the literature $(4,5)$. Separations were obtained with a 30 -meter DB-5MS (J\&W Scientific, Folsom, CA, USA) column having a film thickness of $0.1 \mu \mathrm{m}$ and an inside diameter of $0.25 \mathrm{~mm}$. The optimized chromatogram obtained from a cyclohexane standard is shown in Figure 1. The total sample turn around time for this optimized separation was approximately 25 $\min$. The hydrocarbons were more than adequately separated. Examination of the peaks assigned to the $\mathrm{C}_{27}, \mathrm{C}_{29}, \mathrm{C}_{31}$

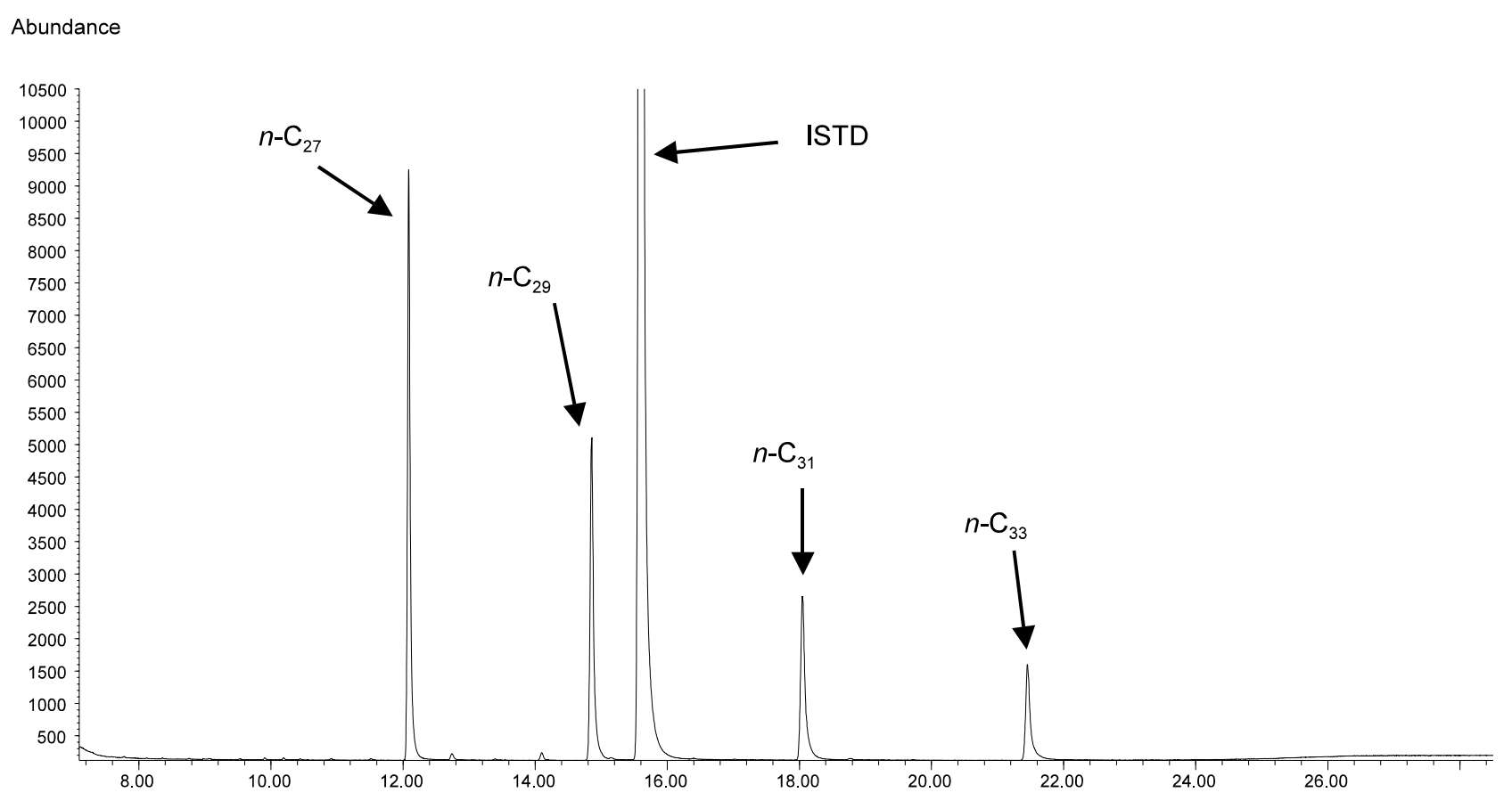

Time

Figure 1. Chromatogram of a standard solution on the 20-meter column GC-MS system 


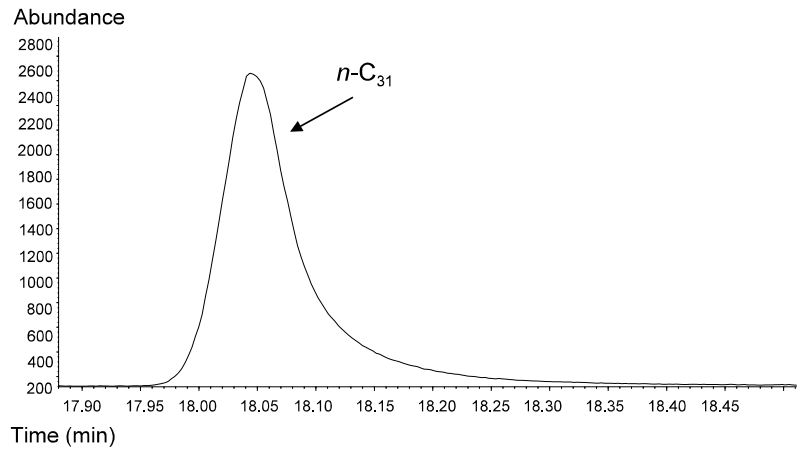

Figure 2. Expanded view of Figure 1 for the hentriacontane peak showing the peak tailing on the GC-MS system

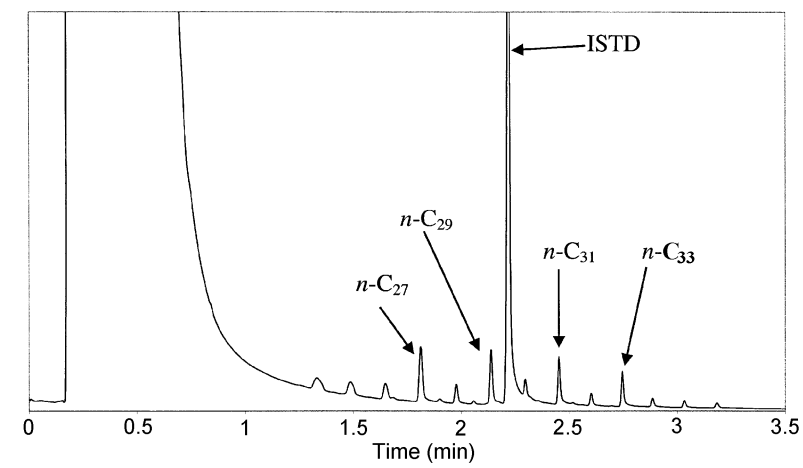

Figure 3. Low standard chromatogram obtained on the ezFLASH system

and $\mathrm{C}_{33}$ hydrocarbons was expanded to include chemical ionization mass spectrometry (CI-MS) by performing the identical separation on an Agilent 6890 GC equipped with a 5973 MSD having CI capability. With methane as the ionization reagent, CI mass spectra were obtained on the $\mathrm{C}_{27}, \mathrm{C}_{29}, \mathrm{C}_{31}$ and $\mathrm{C}_{33}$ hydrocarbons. For those components with retention times corresponding to the selected hydrocarbons in a smoke sample, close examination of the CI mass spectra confirmed the components to: 1) have an appropriate mass and 2) be free of any interferences. Thus, using a DB-5MS column was sufficient to obtain a separation free from any measurable interferences.

Very close examination of the chromatogram obtained from any of the above mentioned separations revealed that the chromatographic profile was consistent with the presence of a "cold" spot in the separation hardware. More specifically, the peaks for the higher molecular weight hydrocarbons of interest, i.e., $\mathrm{C}_{31}$ and $\mathrm{C}_{33}$, possessed a pronounced "tail", Figure 2. The presence of the pronounced skewness or peak asymmetry indicated not only unacceptable chromatographic performance but led to significant and measurable variance in the precision of the method.

In an attempt to eliminate the presence of the "tail", the injection technique was changed to cold on-column while maintaining identical separation and data collection conditions. No change in the peak profiles was noted after this change. Next, the separation was transferred to a second yet identical Agilent 6890 GC/Agilent 5973 MSD system. The peak profiles remained the same. The temperature of the GCMSD interface was increased to the maximum value and yet the presence of tailing was consistent. At this point,

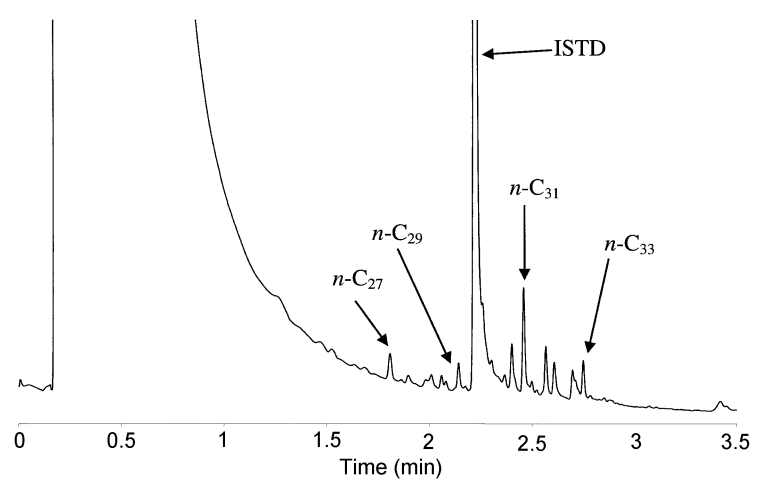

Figure 4. Chromatogram of a smoke sample on the ezFLASH system

the conclusion reached, to account for the tailing, was assigned to the presence of a small but otherwise influential cold spot in the GC-MSD or its interface. One plausible reason for this less than optimal separation performance could possibly be due to the very high boiling points of these hydrocarbons, $>400^{\circ} \mathrm{C}$. Hence, the presence of a minute cold spot in the separation hardware had caused unacceptable chromatographic performance. In an attempt to eliminate the presence of the cold spot and shorten the sample turn around time, the separation was shifted to an ezFLASH system employing an FID.

\section{Separations via ezFLASH/6890 GC}

Following a series of optimization trials with the ezFLASH/ 6890GC/FID, where initial temperature, temperature programming rates, and sample injection volume were examined, the separation depicted in Figure 3 was obtained for a low calibration standard containing the $\mathrm{C}_{27}, \mathrm{C}_{29}, \mathrm{C}_{31}$, and $\mathrm{C}_{33}$ hydrocarbons at a concentration of approximately 0.2 $\mathrm{ng} / \mu \mathrm{L}$ each. All of the peaks were resolved with accompanying very short elution times. The peak width at halfheight was $\leq 0.8 \mathrm{sec}$ for all components. Figure 4 depicts the chromatogram obtained from the extraction of a smoke sample with cyclohexane. The attributes of this chromatogram are very similar to those of the lowest calibration standard. The chromatogram reveals that the hydrocarbons and internal standard are completely resolved from the other components in the smoke sample. In addition, the signal-to-noise ratios for the analytes and the internal standard are very acceptable.

Several important observations can be made by comparing the Agilent $6890 \mathrm{GC} /$ Agilent $5973 \mathrm{MSD}$ and ezFLASH/Agilent 6890 GC/FID based separations: 1) the separation time for the ezFLASH/6890GC system is much shorter, 2) the peak heights for the analytes of interest are much greater for the ezFLASH/6890GC system, and 3) although not specifically illustrated by Figures 3 and 4, the overall cycle time between injections was much less for the ezFLASH/6890GC system, approximately $6 \mathrm{~min}$ vs. approximately $30 \mathrm{~min}$ for the 6890GC system alone.

\section{EzFLASH/6890GC precision studies}

Critical to acceptable performance of any analytical procedure is the precision of the selected approach. To test the 


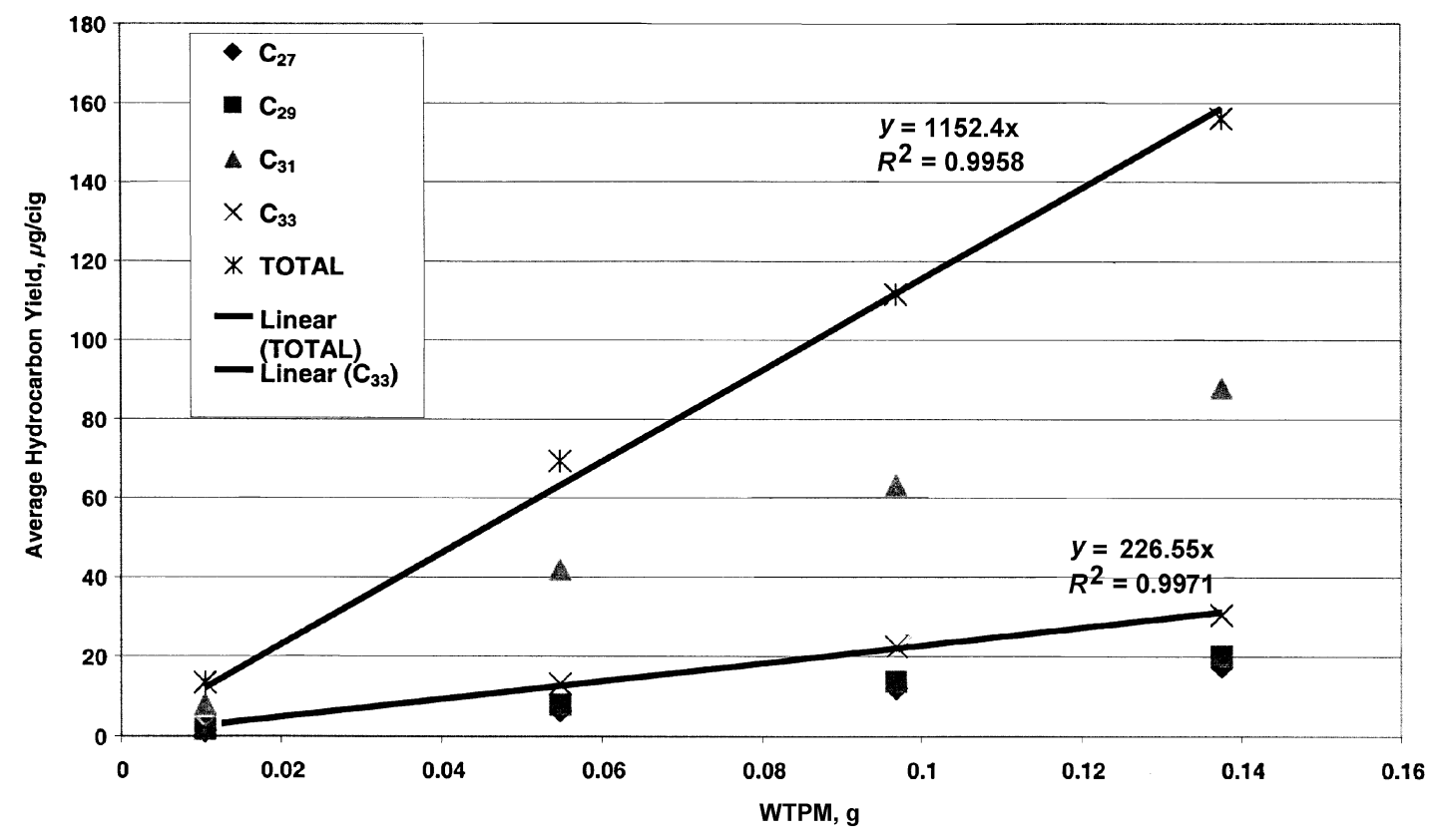

Figure 5. Plot of selected hydrocarbon levels in reference cigarette smoke samples vs. WTPM

precision of the ezFLASH/6890GC/FID system, a series of auto-injections of standard solutions and samples were made. At least six replicate injections were made and the average values, standard deviations and percent relative standard deviations (\%RSD) were calculated. These data can be found in Table 2 .

Also shown in Table 2 are the \%errors obtained by analyzing standard solutions of known concentrations. As can be seen in the table the \%errors for the $10-\mu \mathrm{g} / \mathrm{mL}$ and 5$\mu \mathrm{g} / \mathrm{mL}$ solutions are all below $5 \%$. The lower concentration samples indicated a higher error but still within acceptable ranges.

\section{EzFLASH/6890GC durability}

With the capability of making autoinjections every six minutes, the system durability could become an issue. To test this, the ezFLASH/6890GC/FID system was programmed to make very many injections without interruption. At the completion of approximately 1000 injections, no measurable degradation in the overall performance of the system was noted.

\section{ANALYTICAL RESULTS FROM ezFLASH/6890GC/FID ON SELECTED SMOKE SAMPLES}

An array of University of Kentucky reference cigarettes varying in "tar" levels from approximately 2 to approximately $20 \mathrm{mg} / \mathrm{cig}$ was studied to test the range of applicability of the method for smoke samples. These cigarettes were: 1) $1 \mathrm{R} 5 \mathrm{~F}, 2) 1 \mathrm{R} 4 \mathrm{~F}, 3) 1 \mathrm{R} 3 \mathrm{~F}$, and 4) $2 \mathrm{R} 1 \mathrm{~F}$. The average yields of the $\mathrm{C}_{27}, \mathrm{C}_{29}, \mathrm{C}_{31}$ and $\mathrm{C}_{33}$ hydrocarbons on a per cigarette basis can be found in Table 2 . Recent correlations have been developed linking WTPM yields and "tar" yields with the amounts of selected components (21).
Strong correlations have been found for such analytes as benzo $[a]$ pyrene, phenol, and hydroquinone. Plots of WTPM yields vs. these selected hydrocarbons yields and well as vs. the total amount of the selected hydrocarbons, Figure 5, yielded strong linear correlations .

\section{CONCLUSIONS}

A simple and rapid quantitative method for the determination of linear high molecular weight hydrocarbons in cigarette smoke has been developed. Specifically, the method quantifies the amount of heptacosane $\left(\mathrm{C}_{27}\right)$, nonacosane $\left(\mathrm{C}_{29}\right)$, hentriacontane $\left(\mathrm{C}_{31}\right)$ and tritriacontane $\left(\mathrm{C}_{33}\right)$ in the smoke. After appropriate conditioning, the smoke from five cigarettes is collected on a Cambridge pad and the pad is extracted with $25 \mathrm{~mL}$ of cyclohexane containing approximately $20 \mu \mathrm{g} / \mathrm{mL}$ of triacontane- $\mathrm{d}_{62}$ in a sonic bath for $30 \mathrm{~min}$. The extraction efficiency has been shown to be essentially $100 \%$ for all analytes with precisions of $<10 \%$ RSD. The ezFLASH/GC/FID end determination has a cycle time of $<6$ min thus allowing over 10 injections per hour or 180 injections/day. Since the sample preparation only requires a single step extraction, the smoking process is by far the rate limiting step in the analysis.

The results obtained from the four Kentucky reference cigarettes measured by the method described herein for the determination high molecular weight hydrocarbons in cigarette smoke confirm previous correlations that link the wet total particulate matter (WTPM) yields with the amount of selected smoke constituents. Use of this general approach for the analysis of linear high molecular weight saturated hydrocarbons in tobacco as well as sidestream cigarette smoke would seem readily applicable. Such data would permit the determination of the portion of these alkanes transfer to the cigarette mainstream and sidestream smoke. 


\section{REFERENCES}

1. Kosak, A.I.: The composition of tobacco smoke; Experientia 10 (1954) 69-71.

2. Hoffmann, D., I. Hoffmann, and K. El-Bayoumy: The less harmful cigarette: A controversial issue. A tribute to Ernst L. Wynder; Chem. Res. Toxicol. 14 (2001) 767-790.

3. Rodgman, A.: Environmental tobacco smoke; Regul. Toxicol. Pharmacol. 16 (1992) 223-244.

4. Severson, R.F., R.F. Arrendale, O.T. Chortyk, and M.E. Snook: A method for determining the transfer of lipids from tobacco to smoke; Tob. Sci. 22 (1978) 130-133.

5. Chortyk, O.T., R.F. Severson, and H.C. Higman: Chromatographic determination of hydrocarbons waxes in tobacco leaf and smoke; Beitr. Tabakforsch. 8 (1975) 204-210.

6. Bass, R.T., L.E. Brown, S.B. Hassam, G.C. Newell, Jr., and R.H. Newman: Cigarette smoke formation studies. Transfer of added $\left[18-{ }^{14} \mathrm{C}\right]$ octatriacontane; Beitr. Tabakforsch. Int. 14 (1989) 289-295.

7. Severson, R.F., W.S. Scholtzhauer, O.T. Chortyk, R.F. Arrendale, and M.E. Snook: Precursors of polynuclear aromatic hydrocarbons in tobacco smoke; in: Third International Symposium on Chemistry and BiologyCarcinogenesis and Mutagenesis, edited by P.W. Jones and P. Leber, Ann Arbor Science, Ann Arbor, MI., USA, 1978, pp. 277-298.

8. Barbezat-Debreuil, S.: Etude, aux rayons $\mathrm{X}$, des paraffines du tabac fractionée par chromatographie [Chromatographic analysis of the paraffin fraction of tobacco]; J. Recherche Centre Natl. Sci. Lab. Bellevue (Paris) 45 (1958) 273-277; Compt. Rend. 246 (1958) 2907.

9. Carruthers, W. and R.A.W. Johnstone: Composition of a paraffin wax fraction from tobacco leaf and tobacco smoke; Nature 184 (1959) 1131-1132.

10. Carugno, N.: Determination of paraffin waxes of tobacco and tobacco smoke by gas-liquid chromatography; in: Symposium; Analysis of Carcinogenic Air Pollutants, edited by E. Sawicki and K. Cassel, Natl. Cancer Inst. Monograph 9 (1962) 171-181.

11. Kosak, A.I. and J.S. Swinehart: Some neutral components of cigarette smoke; J. Org. Chem. 25 (1960) 222-225.

12. Lam, J.: Determination of 3,4-benzopyrene and other aromatic hydrocarbons formed by pyrolysis of aliphatic tobacco hydrocarbons; Acta. Path. Microbiol. Scand. 39 (1956) 207-210; 3,4-Benzopyrene as a product of the pyrolysis of aliphatic hydrocarbons; Acta. Path. Microbiol. Scand. 37 (1955) 421-428.

13. Lam, J., B.O. Pedersen and T. Thomasen: Pyrolytic disintegration of selected tobacco constituents and pyrosynthetic formation of aromatic hydrocarbons from cleavage products formed by pyrolysis; Beitr. Tabakforsch. Int. 13 (1985) 1-9.

14. Rodgman, A.: Studies of polycyclic aromatic hydrocarbons in cigarette mainstream smoke: Identification, tobacco precursors, control of levels: A review; Beitr. Tabakforsch. Int. 19 (2001) 361-379.
15. Wynder, E.L. and D. Hoffmann: Studies with the gaseous and particulate phase of tobacco smoke; Proc. Am. Assoc. Cancer Res. 3 (4) (1962) 373; Experimental tobacco carcinogenesis; Adv. Cancer Res. 8 (1964) 249-453; Tobacco and tobacco smoke: Studies in experimental carcinogenesis; Academic Press, New York, NY, 1967, pp. 370-371.

16. Spears, A.W., C.W. Lassiter, and J.W. Bell: The determination of saturated hydrocarbons in cigarette smoke condensate; $16^{\text {th }}$ Tobacco Chemists' Research Conference, Program Booklet and Abstracts, Vol. 16, Paper No. 20, 1962, p 13; Quantitative determination of alkanes in cigarette smoke; J. Gas Chromatogr. 1 (1963) 34-37.

17. Reed, G.L., K.C.-Baker, and H.M. McNair: Fast gas chromatography of various sample types using fast oven temperature programming; J. Chrom. Sci. 37 (1999) 300-305.

18. Williams, T.A., M. Riddle, S.L. Morgan, and W.E. Brewer: Rapid gas chromatographic analysis of drugs of forensic interest; J. Chrom. Sci. 37 (1999) 210-214.

19. Dalluge, J., R. Ou-Aissa, J.J. Vreuls, U.A.Th. Brinkman, and J.R. Veraart: Fast temperature programming in gas chromatography using resistive heating; J. High Resol. Chromatogr. 22 (1999) 459-464.

20. Grall, A., C. Leonard, and R. Sacks: Peak capacity, peak-capacity production rate, and boiling point resolution for temperature-programmed GC with very high programming rates; Anal. Chem. 72 (2000) 591-598.

21. Chepiga, T.A., M.J. Morton, P.A. Murphy, J.T. Avalos, B.R. Bombick, D.J. Doolittle, M.F. Borgerding, and J.E. Swauger: A comparison of the mainstream smoke chemistry and mutagenicity of a representative sample of the US market with two Kentucky reference cigarettes (K1R4F and K1R5F); Food Chem. Toxicol. 38 (2000) 949-962.

Address for correspondence

William M. Coleman

R. J. Reynolds Tobacco Company,

P.O. Box 1487, Winston-Salem,

NC 27102-1487, USA

e-mail:colemaw@rjrt.com 